\title{
The inevitability of change
}

$\mathrm{T}$

he transition of Pain Research $\mathcal{E}$ Management from its traditional mode of publication to its status as an open-access journal is nearly complete. Details are available on the Pain Research $\mathcal{E}$ Management website as well as in the Instructions to Authors, available at www.pulsus.com/pdfs/instruct_pai.pdf. Some background follows.

The most notable advantage to open-access publication is, of course, immediate, free accessibility via the Internet. With a simple keystroke, researchers and clinicians around the world now have ongoing online access to articles published in Pain Research $\mathcal{E}$ Management. Gone will be the frustration associated with finding the reference to an article, but not being able to access the article itself without inconvenience or costs. Pain Research $\mathcal{E}$ Management is widely indexed (Thomson Scientific ISI Web of Knowledge, Current Contents, Embase, Scopus, MEDLINE, ProQuest and PubMed Central) - now, those discovering articles important to them in the Journal will have easy and prompt access. While many of us do have privileged access through library and other subscriptions, many others around the world do not. This will no longer be a problem; we now have a far broader audience, and the impact of research published in the Journal should be greater. It is not surprising that open-access articles are typically cited substantially more often in the professional and scientific literature. The Journal will continue to appear in print, with a current circulation of $>10,000$ copies, and articles accepted for publication will continue to be available prepress in the 'In press' section of the website, accessible to Canadian Pain Society members and subscribers.

There was, of course, considerable reluctance within the Editorial Board of the Journal and on the part of the Canadian Pain Society and its publisher, Pulsus Group Inc, to make this transition, but ultimately the change was supported. The major downside was that it meant publication charges. While there were many pressures to move in this direction, it is conceivable that we would not have done so had there not been major changes in policies and practices initiated by the Pharmaceutical Advertising Advisory Board (PAAB). In particular, the pharmaceutical industry could no longer be relied upon for financial support, as it had been in the past. In a Letter from the Publisher in the July/August 2013 issue of Pain Research $\mathbb{E}$
Management, Robert Kalina, explaining the financial challenges the Journal was confronting, noted that business considerations were of paramount importance.

Other pressures compelling open access were also considerable. The scientific and scholarly communities have long recognized that improved dissemination of advances in knowledge is of great importance; this undoubtedly applies to understanding and controlling pain. Granting agencies have also increasingly demanded greater accessibility to new discoveries supported by public funds. CIHR-supported researchers can now have confidence that the Journal is in full compliance with its Open Access Policy. Traditional publishers were reluctant to provide open access - their funding models typically necessitate access restricted to subscribers or society members. The balance has now shifted toward open access, with publication charges being a major consequence. Fortunately, granting agencies increasingly recognize the necessity of supporting publication. Nevertheless, my sympathies go to newcomers to publishing and others who are less likely to have the requisite financial support. We must innovate on their behalf.

An additional disadvantage is that publication charges appear to be likely to diminish submissions to the Journal for a period of time. Fortunately, the Journal is strong and has enjoyed considerable success in recent years. Submissions have more than doubled, the number of articles published in each issue has increased and the electronic editorial system has been very efficient and substantially reduced the time from submission to editorial decisions. We also have a strong cadre of reviewers who maintain high standards of peer review.

To summarize, open-access journals have many positive attributes, and I expect the Journal to continue to thrive in its new format. I trust that the professional and scientific community will continue to support the Journal as it has in the past. Pain Research $\mathbb{E}$ Management is of great importance to the community committed to greater understanding and control of pain in Canada and across the world.

Kenneth D Craig PhD

Editor-in-Chief, Pain Research \& Management Emeritus Professor of Psychology Distinguished Scholar in Residence,

University of British Columbia Peter Wall Institute for Advanced Studies 


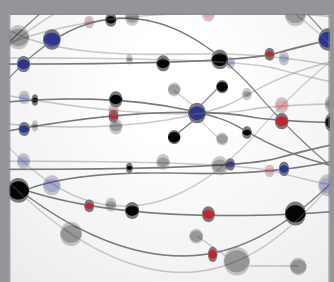

The Scientific World Journal
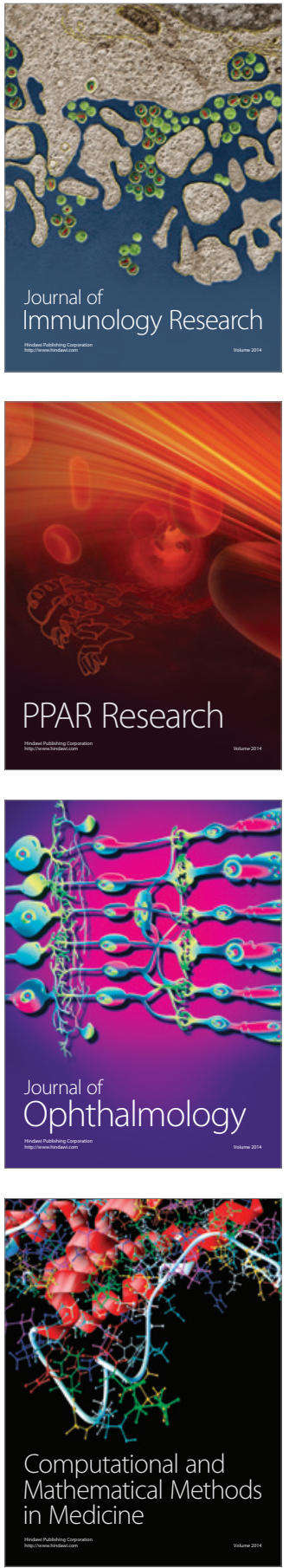

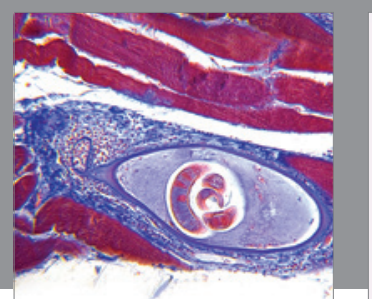

Gastroenterology Research and Practice

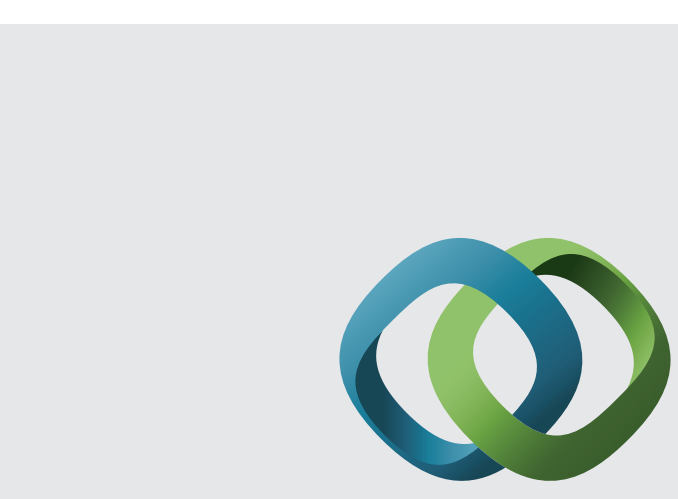

\section{Hindawi}

Submit your manuscripts at

http://www.hindawi.com
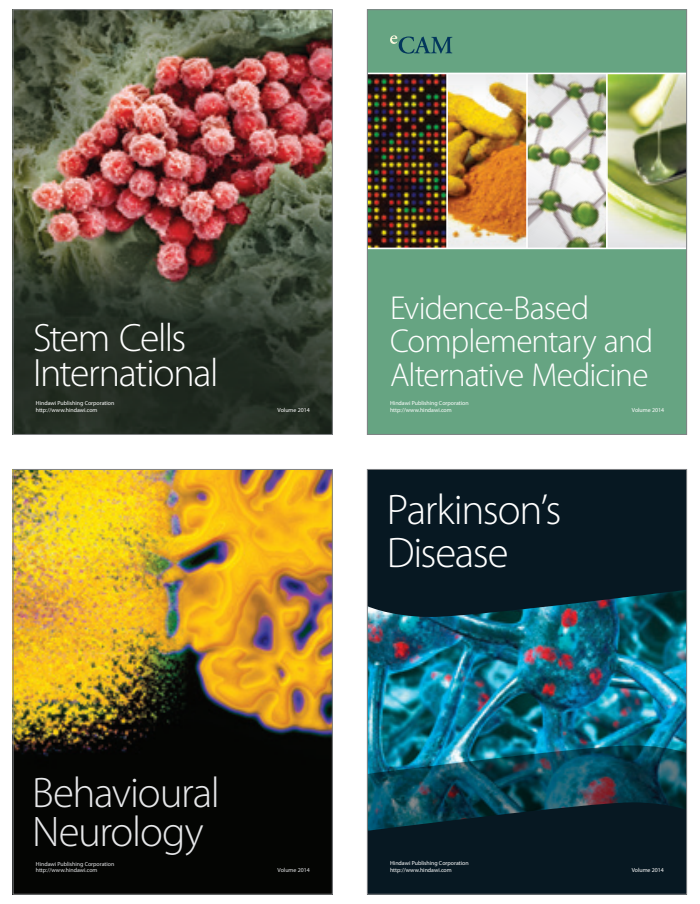
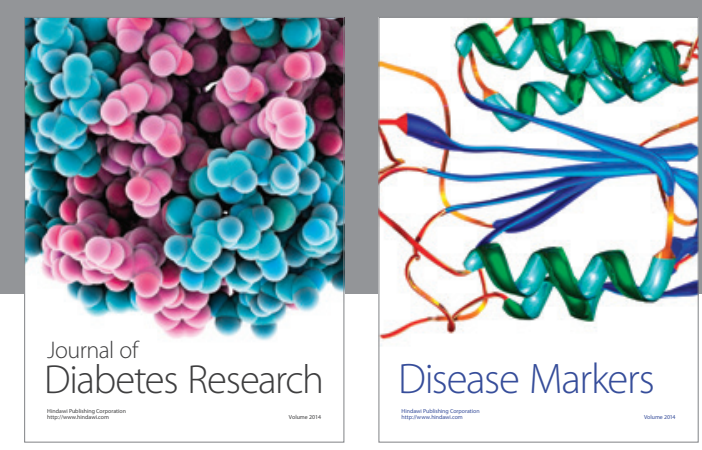

Disease Markers
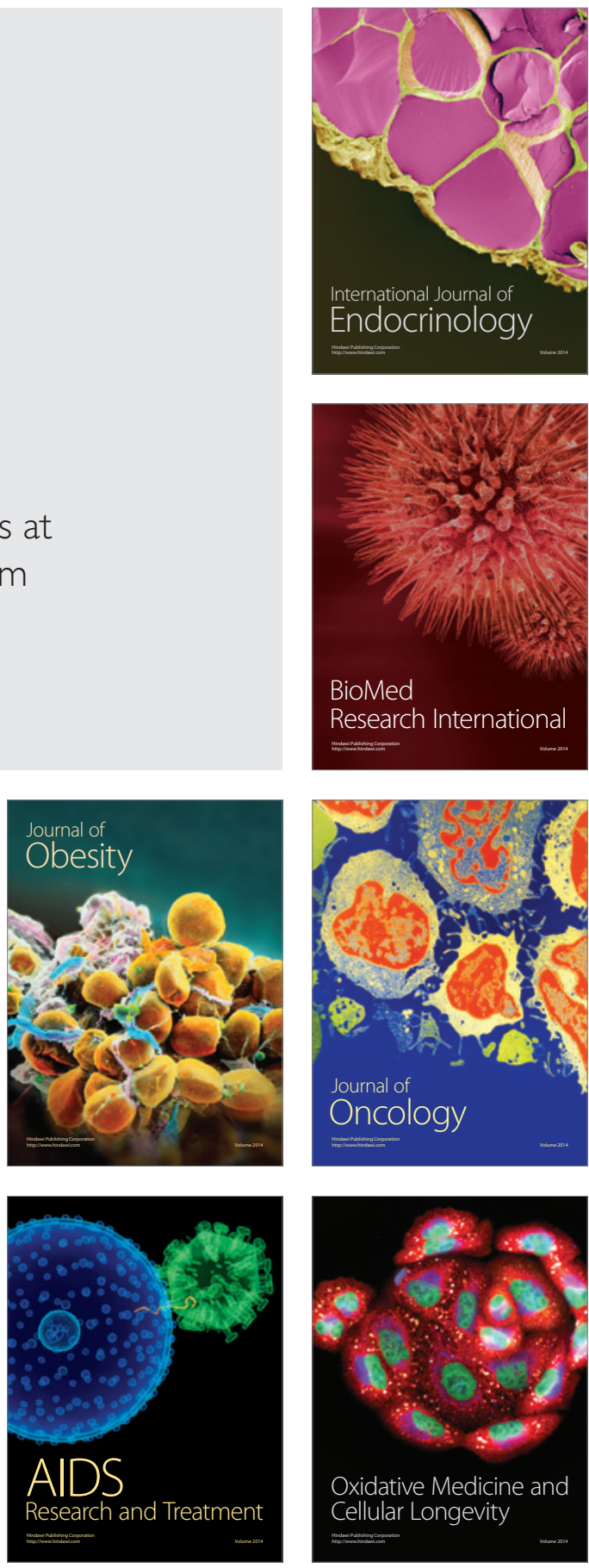